\title{
Gradhiva
}

GRADHIV

Revue d'anthropologie et d'histoire des arts

$24 \mid 2016$

ARTchives

\section{Gaetano Ciarcia, Le Revers de l'oubli : mémoires et commémorations de l'esclavage au Bénin}

Paris, Karthala/Ciresc, coll. « Esclavages », 2016

\section{Joël Noret}

\section{OpenEdition}

\section{Journals}

Édition électronique

URL : http://journals.openedition.org/gradhiva/3307

DOI : $10.4000 /$ gradhiva.3307

ISSN : 1760-849X

\section{Éditeur}

Musée du quai Branly Jacques Chirac

Édition imprimée

Date de publication : 7 décembre 2016

Pagination : 249

ISBN : 978-2-35744-094-4

ISSN : 0764-8928

\section{Référence électronique}

Joël Noret, « Gaetano Ciarcia, Le Revers de l'oubli : mémoires et commémorations de l'esclavage au Bénin », Gradhiva [En ligne], 24 | 2016, mis en ligne le 07 décembre 2016, consulté le 24 septembre 2020. URL : http://journals.openedition.org/gradhiva/3307 ; DOI : https://doi.org/10.4000/gradhiva.3307

Ce document a été généré automatiquement le 24 septembre 2020.

(C) musée du quai Branly 


\section{Gaetano Ciarcia, Le Revers de l'oubli :} mémoires et commémorations de l'esclavage au Bénin

Paris, Karthala/Ciresc, coll. « Esclavages », 2016

Joël Noret

\section{RÉFÉRENCE}

Gaetano Ciarcia, Le Revers de l'oubli : mémoires et commémorations de l'esclavage au Bénin, Paris, Karthala/Ciresc, coll. « Esclavages », 2016, 200 p. 


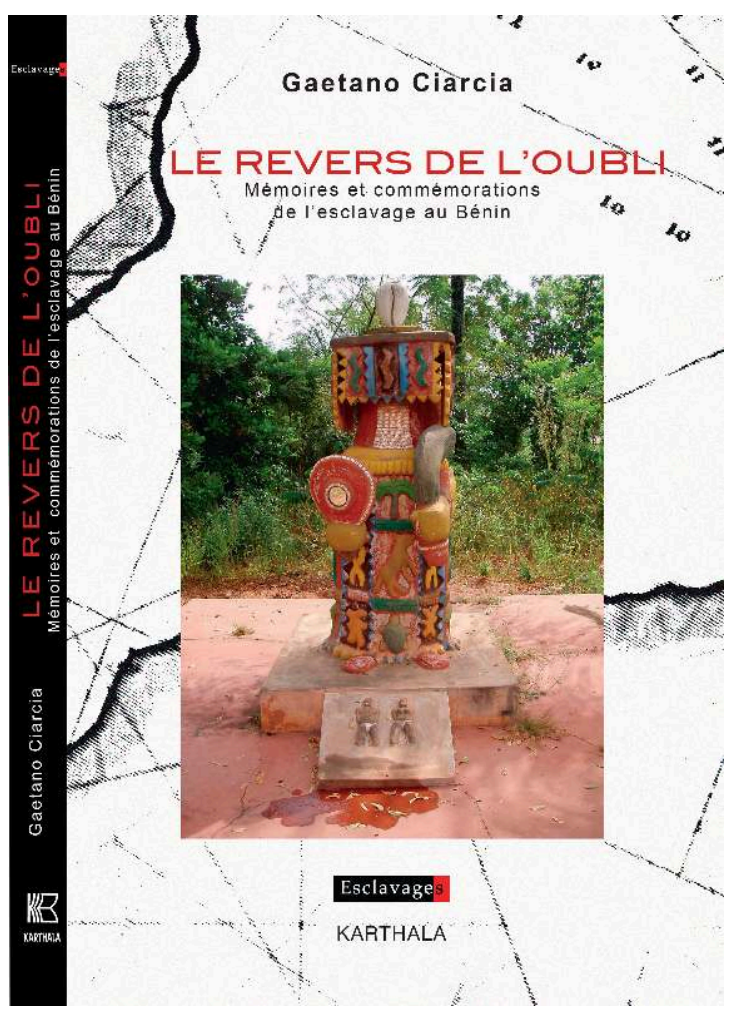

1 Le livre de Gaetano Ciarcia porte sur la genèse et le déploiement actuel, au Bénin, de «l'institution culturelle» de mémoires de l'esclavage articulées aux cultes vodun. Fondamentalement, Ciarcia scrute les déplacements de significations induits par le processus de patrimonialisation de la traite négrière et de la religion «traditionnelle ", ainsi que les enjeux multidimensionnels du sens moral et politique donné au passé. L'ouvrage analyse le travail de "re-sémantisation » et de "transfiguration » du passé de l'esclavage lié à l'institution en cours de la traite comme héritage moral patrimonial. Ce travail mémoriel passe en particulier aujourd'hui par "la mise en œuvre d'un dispositif de symboles : monuments, cérémonies, discours » (p. 13). Dès lors, Ciarcia se livre au fil de l'ouvrage à une ethnographie de différents groupes d'acteurs impliqués dans l'entreprise de patrimonialisation : cadres du ministère de la Culture, instances nationales et internationales, élites politiques locales, guides touristiques, représentants d'associations de la "diaspora", chefs de cultes, intellectuels et universitaires béninois, etc. Dans ce paysage complexe et mouvant, il suit la construction des récits émergeant des rencontres et de la confrontation entre ces différents mondes et leurs visions du passé.

2 L'ouvrage est divisé en deux parties équilibrées, l'« institution d'un héritage » d'abord, la « formation d'une mémoire culturelle » ensuite. La première revient sur l'origine des initiatives patrimoniales menées à Ouidah dans les années 1980, avant de montrer comment celles du nouveau régime démocratique des années 1990 opèrent une articulation entre revitalisation des cultes vodun et institution de la traite en moment historique fondateur. Puis les deux dernières décennies verront se multiplier les initiatives patrimoniales, lesquelles entrent parfois en tension avec d'autres mémoires, lignagères notamment, comme dans le cas des célébrations familiales annuelles à la gloire du négrier Francisco Félix de Souza, figure locale éminente de la traite au XIX siècle encore commémorée de nos jours par ses descendants, en toute bonne conscience, pour ainsi dire (p. 51-54). Ainsi, entre les perspectives issues de certaines 
composantes de la diaspora afro-américaine, qui promeuvent «un passé pardonné, mais non pas oublié » (p. 70), et les mémoires plus nostalgiques qui se donnent à voir, par exemple dans la famille de Souza ou dans les récits du passé de certains descendants des familles royales aboméennes, l'espace des points de vue s'avère en fait aussi divisé et lourd de conflits latents que celui des positions sociales, lui aussi marqué par des écarts importants.

3 La seconde partie de l'ouvrage engage un "examen généalogique » du statut de l'histoire et de la culture locales à partir «des pratiques ethnographiques et missionnaires» (p. 27) dans le Dahomey de l'époque coloniale, celles-ci ayant jeté certaines bases des conceptions à l'origine des réinterprétations contemporaines du passé de l'esclavage et de la tradition vodun. Ici, Ciarcia propose une généalogie des idées ayant mené à l'émergence d'un regard patrimonial sur la culture locale dans un certain nombre de discours portant aujourd'hui sur la traite. Et c'est principalement dans le christianisme, en particulier dans le catholicisme missionnaire de l'époque coloniale, qu'il identifie la matrice de ces rhétoriques contemporaines. C'est en effet dans l'ethnographie missionnaire, engagée localement par le père Aupiais et ses collaborateurs, et à travers la scolarisation, marquée par une forte "emprise missionnaire » (p. 94) sur les futures élites coloniales, que se met en place un rapport patrimonial à la culture locale et aux cultes vodun. Pour autant, entre milieux chrétiens aujourd'hui promoteurs de l'idée de repentir et acteurs de la valorisation du vodun comme religion de l'authenticité africaine, les écarts de perspectives restent bien réels. Dans le même temps, le champ des producteurs de mémoires est aussi occupé par la quête partagée du développement économique. D'où la lecture de Ciarcia qui voit derrière certains des projets et des discours engagés dans la double patrimonialisation de la traite et des cultes vodun « l'attente millénariste d'une ère de plénitude culturelle et de développement économique» (p. 114). Par-delà toutefois la diversité des rhétoriques mémorielles et la distance sociale entre les groupes d'acteurs engagés dans l'entreprise patrimoniale, Ciarcia repère aussi le souci récurrent d'un consensus susceptible de satisfaire a minima les différentes parties, qui passe par une logique de l'extraversion - la référence à Bayart et à l'idée d'une instrumentalisation des ressources pouvant être captées de l'extérieur est ici implicite mais bien réelle menant à une forme de malléabilité des discours en fonction des audiences.

4 En conclusion, il apparaît donc que ce qui est à l'œuvre dans les entreprises de patrimonialisation d'aujourd'hui peut être caractérisé comme un "oubli créateur ", producteur d'effets positifs par le biais du réarrangement des séquences historiques, et opérant à travers "des scénographies muséales et rituelles»(p. 180), lesquelles revisitent le passé de la traite pour en faire "un héritage moral et cérémoniel diasporique » (p. 181). Au final, Ciarcia livre ici un ouvrage fouillé et dense, soutenu par plusieurs années de recherches, qui retiendra l'attention de tous ceux qui s'intéressent à la complexité des mémoires de l'esclavage dans le monde atlantique. 


\section{AUTEURS}

JOËL NORET

noret@ulb.ac.be 